\section{Emergent ECLS for life-threatening severe cardiac dysfunction as presentation of H1N1-flu}

\author{
Massimo Bonacchi, Marco Ciapetti1, Gabriella Di Lascio*, \\ Guy Harmelin, Guido Sani, Adriano Peris' ${ }^{1}$ \\ Cardiac Surgery Functional Unit and *Postgraduate School of \\ Anesthesia and Intensive Care, Department of Sperimental and \\ Clinical Medicine; University of Florence-Italy \\ 1Department of Anesthesia and Intensive Care Unit of Emergency, \\ Careggi Teaching Hospital; Florence-Italy
}

\section{Introduction}

The H1N1-flu affected primary young and female patients without major comorbidities (1-3).

Although most of the confirmed cases have been self-limited and uncomplicated febrile respiratory illness, there have been severe infection with complications or mortality as well. In some cases, extracorporeal membrane oxygenation (ECMO) was commenced for the treatment of refractory hypoxemia, hypercapnia, or both, which occurred despite mechanical ventilation and rescue conventional therapies (4).

Here, we report the first case of atypical clinical presentation of H1N1-infection that was successfully treated with extracorporeal membrane oxygenation (ECMO) in Florence.

The study protocol was approved by the Ethic committee of the institution. The patient parents read and signed the disclosure information form.

\section{Case Report}

An otherwise healthy 15-year-old white man, presented to our emergency department with fever and lethargy. His medical history was uneventful.

Examination on arrival was significant for altered mental status, ataxia and hypotension with mottled extremities. His vital signs included a temperature of $39.8^{\circ} \mathrm{C}$, blood pressure $80 / 40 \mathrm{~mm} \mathrm{Hg}$, a pulse rate of 115 beats/minute, respiratory rate 30 breaths/minute. He had diminished breath sounds and bilateral lower-extremity edema. The patient became more hypotensive and lost consciousness, his respiratory status rapidly progressed to respiratory failure $\left(\mathrm{PaO}_{2} / \mathrm{FiO}_{2}=111.9, \mathrm{PaCO}_{2}=113 \mathrm{~mm} \mathrm{Hg}\right)$ although endotracheal intubation and mechanical ventilator support.

Chest radiography revealed consolidation and collapse of the right lower lobe (Fig. 1 a).

A two-dimensional TTE revealed poor cardiac contractility with a left ventricular ejection fraction( LVEF) $=31 \%$ (Fig. 2 a).

The patient remained hemodynamically unstable with poor perfusion on maximal conventional therapy (Table 1), hypoxiemic and hypercapnemic. Given the reasonable likelihood of recovery of cardiac function, we chose ECMO support and, despite the severe left ventricular (LV) dysfunction, veno-venous (VV) ECMO was adopted because we believed that the real problem were the uncontrollable hypoxia and hypercapnia. ECMO implantation was attempted via femoro-jugular access with our innovative cannulation technique ( $\chi$-configuration) as previously reported (5).

On day 1 real-time reverse transcriptase-polymerase chain reaction of respiratory sample for $\mathrm{H} 1 \mathrm{~N} 1$ virus showed positive results. The patient was treated with oseltamivir $150 \mathrm{mg}$ twice daily.

Table 1. Hemodynamic parameters of the refractory severe CS in H1N1 patient treated with extracorporeal life support

\begin{tabular}{|c|c|c|c|c|c|}
\hline & $\begin{array}{l}\text { 1h before } \\
\text { ECMO }\end{array}$ & $\begin{array}{c}12 \mathrm{~h} \\
\text { after ECMO }\end{array}$ & $\begin{array}{c}\text { Day } 2 \\
\text { on ECMO }\end{array}$ & $\begin{array}{c}\text { Day } 5 \\
\text { on ECMO }\end{array}$ & $\begin{array}{c}\text { 12h after ECMO } \\
\text { explantation }\end{array}$ \\
\hline \multicolumn{6}{|l|}{ Hemodynamic variables } \\
\hline MAP, $\mathrm{mm} \mathrm{Hg}$ & 40 & 80 & 82 & 95 & 80 \\
\hline Spontaneous cardiac index $(1 / \mathrm{min}-\mathrm{m}-2)^{\mathrm{a}}$ & 1.8 & 2.2 & 3.4 & 3.8 & 3.8 \\
\hline Left ventricular ejection fraction $(\%)^{a}$ & 20 & 30 & 40 & 50 & 60 \\
\hline ECMO assistance, L/min & - & 5 & 5.5 & 3.5 & - \\
\hline \multicolumn{6}{|l|}{ Organ perfusion variable } \\
\hline $\mathrm{PaO}_{2} / \mathrm{FIO}_{2}, \mathrm{~mm} \mathrm{Hg}$ & 48 & 315 & 321 & 222 & 246 \\
\hline $\mathrm{SvO}_{2}, \%$ & 47.8 & & & & 86.0 \\
\hline Plasma lactate concentration, $\mathrm{mmol} / \mathrm{L}$ & 6.7 & 2.9 & 1.4 & 1.5 & 1.1 \\
\hline Serum creatinine concentration, $\mathrm{mg} / \mathrm{dL}$ & 2.5 & 1.48 & 1.11 & 0.76 & 0.62 \\
\hline Prothrombine time, $\%$ & 34 & 47 & 54 & 70 & 69 \\
\hline \multicolumn{6}{|l|}{ Doses of vasoactive drugs } \\
\hline Epinephrine, $\mu \mathrm{g} / \mathrm{kg} / \mathrm{min}$ & 1.5 & 0.8 & - & - & - \\
\hline Norepinephrine, $\mu \mathrm{g} / \mathrm{kg} / \mathrm{min}$ & 1.9 & 0.5 & 0.2 & - & - \\
\hline Dobutamine, $\mu \mathrm{g} / \mathrm{kg} / \mathrm{min}$ & 20 & & 10 & 7 & - \\
\hline
\end{tabular}



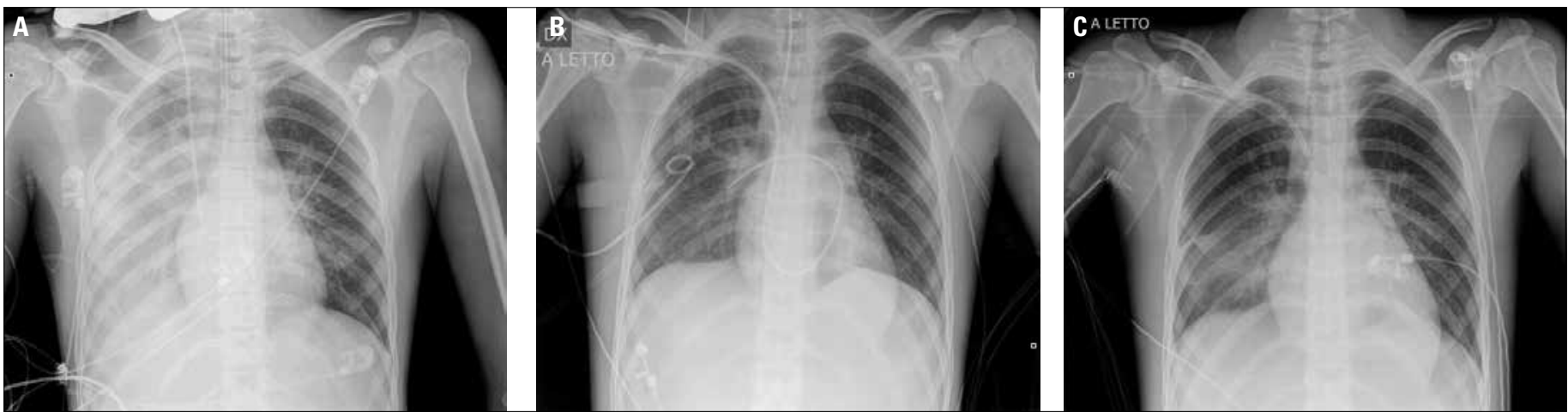

Figure 1. Evolution of chest X-ray shows diffuse airspace disease with interstitial alveolar infiltrate/consolidation on ICU admission (A), on day 4 after ECMO a partial resolution of the finding (B) and near complete resolution of the pulmonary infiltrates at ICU discharge (C)
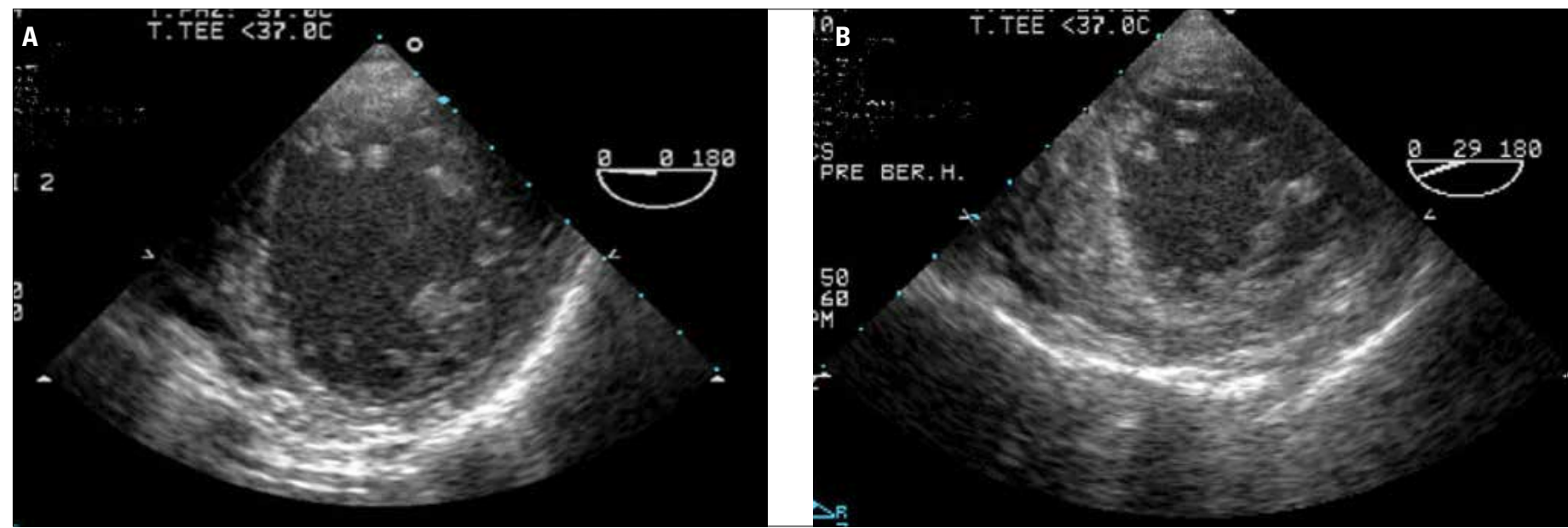

Figure 2. Serial echocardiograms obtained in patient in term of LV function and motion. (A) before ECMO. (B) after ECMO

During ECMO assistance inotropic agents were rapidly tapered and withdrawn on day 2 (Table 1).

As reported in Table 2, in the first 2 days ECMO flow was fixed at 5 $\mathrm{L} / \mathrm{min}$, this in order to obtain systemic blood saturation of $>95 \%$.

On day 4 of ECMO, lung functions and Rx significantly improved dramatically (cleaning of infiltrates, Fig. 1b).

VV-ECMO weaning was started and support was reduced by progressive extracorporeal blood-flow lessening as previous reported (5).

On day 6, the patient was trailed-off the ECMO. Subsequent to weaning patient from ECMO, he remained on mechanical ventilation until standard extubation criteria were met.

The patient's post-ECMO course too was uneventful with no ECMO complications associated.

A transthoracic echocardiogram 4 days subsequent to ECMO explantation showed a good left ventricular contractility (LVEF=65\%) (Fig. 2b) and a chest radiographs (Fig. 1c) revealed significant clearing of the parenchymal infiltrates. The patient was discharged from the ICU and transferred to the medical ward, and he was discharged on hospital day 15.

A 1-month, 6-month and 12-month follow- up, the patient was well and showed complete and stable cardiac recovery without neurological sequelae: his ejection fraction remained stable without any sign of regional dyssinergy.

\section{Discussion}

Seasonal and novel (H1N1-09) influenza commonly present with a costellation of symptoms known as influenza-like illness and complications in extra-respiratory tissues, such as encephalopathy, myocarditis and myopathy occur occasionally (6).

Our patient didn't present with a classic influenza-like illness in the initial phase of the infection: the patient had signs and symptoms of cardiogenic hypoperfusion and neurologic alterations as initial presentation. In our case, V-V ECMO was chosen as a mechanical support against uncontrollable hypoxia and hypercapnia. It was also the right supportive therapy for heart failure.

\section{Conclusion}

Relevant clinical conclusion can be drawn from this report.

First, influenza H1N1 infection can occur with cardiac dysfunction without flu-like symptoms. It is important to recognize that patient with heart failure might have influenza infection, so should indicate testing for H1N1 infection, because early diagnosis is required for adequate treatment.

Second, extracorporeal membrane oxygenation may produce excellent results in such critically patients and should be considered before end stage multiorgan failure develops in such patients. 
Table 2. Respiratory and Hemodynamic parameters during ICU stay and ECMO

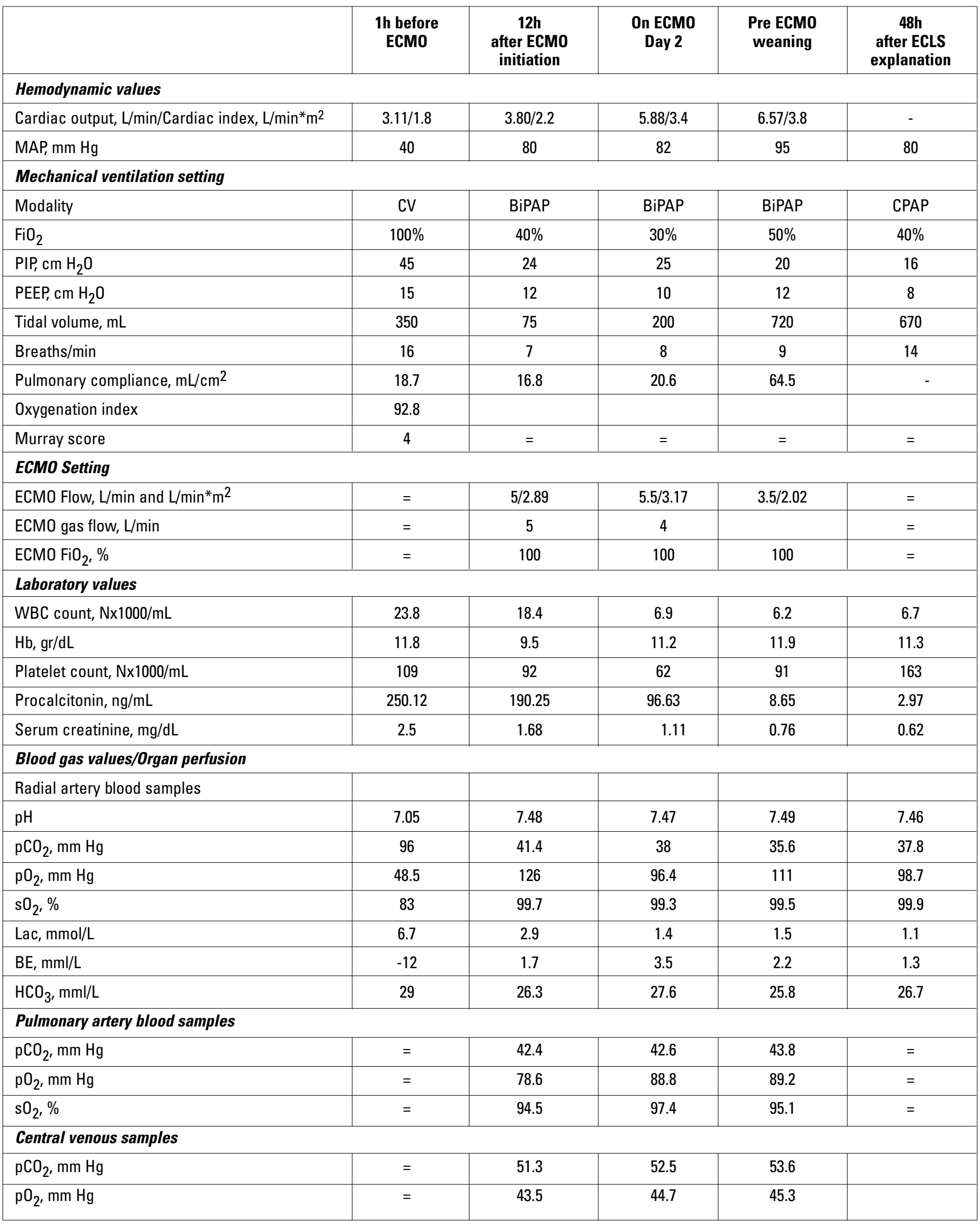




\begin{tabular}{|c|c|c|c|c|c|}
\hline $\mathrm{ScvO}_{2}, \%$ & $=$ & 66.5 & 74.6 & 73.8 & \\
\hline \multicolumn{6}{|l|}{ Pre-Oxygenator samples } \\
\hline $\mathrm{pCO}_{2}, \mathrm{~mm} \mathrm{Hg}$ & $=$ & 50.6 & 51.4 & 55.2 & $=$ \\
\hline $\mathrm{sO}_{2}, \%$ & $=$ & 66.5 & 74.6 & 74.4 & $=$ \\
\hline \multicolumn{6}{|l|}{ Post-Oxygenator samples } \\
\hline $\mathrm{pO}_{2}, \mathrm{~mm} \mathrm{Hg}$ & $=$ & 412.6 & 424 & & $=$ \\
\hline $\mathrm{sO}_{2}, \%$ & $=$ & 100 & 100 & 100 & $=$ \\
\hline $\begin{array}{l}\mathrm{BRF} \% \\
\left(\mathrm{PreOxy} \mathrm{s} \mathrm{O}_{2}-\mathrm{ScO}_{2}\right) /\left(\mathrm{PostO}_{2} \mathrm{xy} \mathrm{s} \mathrm{O}_{2}-\mathrm{ScO}_{2}\right) \times 100\end{array}$ & $=$ & 5.54 & 5.07 & 1.95 & $=$ \\
\hline
\end{tabular}

Patients $B S A=1.73 \mathrm{~m}^{2}$. All reported data are the mean of 3 consecutive measures.

ABE - base excess; BiPAP - bi-levels positive airways pressure; BRF - blood recirculation fraction with calculation formula (17); BSA - body surface area; CI - cardiac index; CPAP continuous positive airways pressure; $\mathrm{CV}$-controlled volume; $\mathrm{CO}$ - cardiac output; $\mathrm{ECMO}$ - extracorporeal membrane oxygenation; $\mathrm{FiO}_{2}$ - fraction inspired oxygen; $\mathrm{Hb}$ - $\mathrm{Hemoglobin}$ concentration; $\mathrm{Hb}$ - Hemoglobin concentration; $\mathrm{HCO}_{3}$ - bicarbonate concentration; MV - respiratory minute volume; Lac - lactate concentration; PEEP - positive end-expiratory pressure; PIP - peak inspiratory pressure; $\mathrm{paCO}_{2}$ - arterial carbon dioxide tension; $\mathrm{paO}_{2}$ - arterial oxygen tension; $\mathrm{WBC}$ - white blood cells; $\mathrm{SO}_{2}$ - oxygen saturation; $\mathrm{ctO}_{2}$ - $0 \mathrm{Oxygen} \mathrm{Content}_{3}$ $\mathrm{ScvO}_{2}$ - central-venous oxygen saturation; TV - tidal volume

\section{References}

1. Dawood FS, Jain S, Finelli L, Shaw MW, Lindstrom S, Garten RJ, et al; Novel Swine-Origin Influenza A (H1N1) Virus Investigation Team. Emergence of a novel swine-origin influenza A (H1N1) virus in humans. N Engl J Med 2009; 360: 2605-15. [CrossRef]

2. Kumar A, Zarychanski R, Pinto R,Cook DJ,Marshall J,Lacroix J, et al. Critically ill patients with 2009 Influenza A (H1N1) infection in Canada. JAMA 2009; 302: 1872-9. [CrossRef]

3. Martin GS, Mannino DM, Eaton S, Moss M. The epidemiology of sepsis in the United States from 1979 through 2000. N Engl J Med 2003; 348: 1546-54. [CrossRef]

4. Davies A, Jones D, Bailey M, Beca J, Bellomo R, Blackwell N, et al; The Australia and New Zealand Extracorporeal Membrane Oxygenation (ANZ ECMO) Influenza Investigators. Extracorporeal Membrane Oxygenation for 2009 Influenza $A(H 1 N 1)$ acute respiratory distress syndrome. JAMA 2009; 302: 1888-95. [CrossRef]

5. Bonacchi M, Harmelin G, Peris A, Sani G. A novel strategy to improve systemic oxygenation in venovenous extracorporeal membrane oxygenation: the " $\chi$-configuration". J Thorac Cardiovasc Surg 2011; 142: 1197-204. [CrossRef]

6. Mamas MA, Fraser D, Neyses L. Cardiovascular manifestations associated with influenza virus infection. Int J Cardiol 2008; 130: 304-9. [CrossRef]

Address for Correspondence: Dr. Massimo Bonacchi, Cardiac Surgery Department of Sperimental and Clinical Medicine, University of Florence, Viale Morgagni, 8550134 Firenze-Italy

Phone: 393389855782

Fax: 3936338955782

E-mail: massimo.bonacchi@unifi.it

Available Online Date: 18.12 .2013

(C) Copyright 2014 by AVES - Available online at www.anakarder.com doi:10.5152/akd.2013.5139

\section{Spontaneously regressed congenital idiopathic dilatation of the right atrium in the newborn}

\author{
Abdullah Özyurt, Ali Baykan, Mustafa Argun, Özge Pamukçu, \\ Ertuğrul Mavili*, Nazmi Narin \\ Department of Pediatric Cardiology and *Pediatric Radiology, Faculty \\ of Medicine, Erciyes Univesity; Kayseri-Turkey
}

\section{Introduction}

Idiopathic dilatation of the right atrium (IDRA) is an uncommon cardiac abnormality that consists of a disproportionately enlarged right atrium (RA) in the absence of any other anatomical pathology of the heart (1). Appropriate treatment of IDRA is controversial. Accurate diagnosis is necessary for proper medical and surgical management. Although long-term follow-up literature reports have been limited, the number of authors supporting RA surgical treatment is more than the ones supporting medical follow-up (2-5). Up to date, only few cases have been diagnosed. In this report we want to present an asymptomatic case with giant RA dilatation diagnosed by fetal echocardiography which was regressed spontaneously.

\section{Case Report}

Right atrial dilatation was seen in the fetal echocardiography of 18-week-old fetus and followed up till birth without having any rhythm problems. She was born at gestational 40 week weighting $3800 \mathrm{gr}$ with spontaneous vaginal delivery. Her parents have a second degree relationship marriage with no history of known disease in the family. Clinical examination revealed tachypnea and mild respiratory distress but not cyanotic at postnatal first day. Auscultation revealed systolic murmur best heard at the left upper sternal edge. A 12-lead electro- 
Copyright of Anatolian Journal of Cardiology / Anadolu Kardiyoloji Dergisi is the property of Aves Yayincilik Ltd. STI and its content may not be copied or emailed to multiple sites or posted to a listserv without the copyright holder's express written permission. However, users may print, download, or email articles for individual use. 